\title{
Autism, social cognition and superior temporal sulcus*
}

\author{
Monica Zilbovicius ${ }^{1 \#}$, Ana Saitovitch ${ }^{1}$, Traian Popa ${ }^{2}$, Elza Rechtman ${ }^{1}$, Lafina Diamandis ${ }^{1}$, \\ Nadia Chabane $^{1,3}$, Francis Brunelle ${ }^{1}$, Yves Samson ${ }^{4}$, Nathalie Boddaert ${ }^{1}$ \\ ${ }^{1} \mathrm{U} 1000$ Brain Imaging in Psychiatry, INSERM-CEA, Pediatric Radiology Service, Necker Enfants Malades Hospital, Paris V René \\ Descartes University, Paris, France \\ ${ }^{2}$ Neuroimage Research Center, ICM, Paris, France \\ ${ }^{3}$ Child Psychiatry Service, Robert Debre Hospital, Paris, France \\ ${ }^{4}$ Stroke Unity, Pitié-Salpêtrière Hospital, Paris VI Pierre et Marie Curie University, Paris, France \\ Email: "mozilbo@gmail.com
}

Received 28 February 2013; revised 31 March 2013; accepted 8 April 2013

Copyright (C) 2013 Monica Zilbovicius et al. This is an open access article distributed under the Creative Commons Attribution License, which permits unrestricted use, distribution, and reproduction in any medium, provided the original work is properly cited.

\begin{abstract}
Results on brain imaging studies have led to a better understanding of the neural circuits involved in social cognition and its implication in autism spectrum disorders (ASD). It has been shown that the superior temporal sulcus (STS) is highly implicated in social processes, from perception of socially relevant information, such as body movements or eye gaze, to more complex social cognition processes. Furthermore, several multimodal brain imaging results point to anatomo-functional abnormalities in the STS in both children and adults with ASD. These results are highly consistent with social impairments in ASD, among which eye gaze perception is particularly relevant. Gaze abnormalities can now be objectively measured using eye-tracking methodology, leading to a better characterization of social perception impairments in autism. Moreover, these gaze abnormalities have been associated with STS abnormalities in ASD. Based on these results, our hypothesis is that anatomo-functional anomalies in the STS occurring early across brain development could constitute the first step in the cascade of neural dysfunction underlying autism. In the present work, we'll review recent data of STS contribution to normal social cognition and it's implication in autism.
\end{abstract}

Keywords: Brain Imaging; Social Cognition; Autism; STS

*Funding: Fondation de France, Fondation Orange, PHRC. The funders had no role in study design, data collection and analysis, decision to publish, or preparation of the manuscript.

The authors declare no conflicts of interest in this study.

${ }^{\#}$ Corresponding author.

\section{INTRODUCTION}

Brain imaging studies developed during the last decade have led to a better understanding of the neural circuits involved in social cognition. By identifying brain regions involved in social perception, these studies have also allowed a better understanding of the neural circuits involved in autism spectrum disorders (ASD).

Based on electrophysiology studies in non-human primates, Brothers defined the social brain as a network of brain regions, composed by the amygdala, the orbitofrontal cortex (OFC), the inferotemporal face-responsive regions and the superior temporal sulcus (STS) [1]. In humans, during the last decade, several brain imaging studies have confirmed Brothers' model of the social brain, revealing the neural structures implicated in different aspects of social cognition [2-5]. More recently, researchers have focused on an aspect of the social brain which can broadly be called "social perception”, domain in which it is now clear that the STS is a key player.

The STS, particularly in the right hemisphere, seems to play a major role in social perception processing by analyzing biological motion cues, such as gaze direction, body movements and facial expressions, in order to detect, interpret and predict the actions and intentions of others [2,4-9]. Deficits in such social perception processing are central symptoms in ASD. In addition, several multimodal brain imaging results point to anatomo-functional abnormalities in the STS in both children and adults with ASD [10-14]. Based on these results, our data-drive hypothesis is that STS abnormalities occurring early across brain development could constitute the first step in the cascade of abnormal neural phenomena underlying autism, therefore supporting the major implication of STS abnormalities in ASD [2,15].

Among social impairment symptoms in autism, defi- 
cits in using information concerning eye gaze to understand other's mental states and intentions are particularly striking $[16,17]$. Recently, the use of eye-tracking methodology has allowed a better characterization of the social perception deficits in ASD, particularly a lack of preference for the eyes. Such deficits can be related to the STS abnormalities described in autism. In this review, we will focus on the implications of the STS in normal and abnormal social perception processes, more specifically in eye gaze processing.

\subsection{Social Perception and Social Cognition: From Typical Development to Autism}

Interacting with others in the environment requires that we perceive and recognize their movements and actions. The capacity to distinguish biological agents from nonbiological ones plays a critical role in the process of adaptive behavior. Several studies have demonstrated that, from a very early stage in development, the human visual system is particularly sensitive to biological motion [1820]. Visual processing of biological motion produced by living organisms is of immense value for successful daily-life activities and, in particular, for adaptive social behavior and nonverbal communication [21]. From the very first hours of life, human newborns give preferential attention to people, and this tendency persists during development. At four-day-old, they distinguish a face looking toward them from a face looking away; by threemonth-old, infants look more at a person's eyes than at other parts of the face [22]; by four months of age, infants exhibit a visual preference for upright over upsidedown point light figures $[23,24]$. These findings demonstrate that, from a very early stage in development, humans exhibit a preferential processing of social information among different stimuli. This preferential processing will be the foundation for the development of what may be called a "social expertise", which will play a major role in the subsequent development of all social interaction processes [25].

Indeed, making eye contact is the most powerful mode of establishing a communicative link between humans [22]. Since Kanner's classical clinical description, it is known that eye contact is severely disrupted in autism. Such a deficit prevents normal social interaction, including the ability to understand other's mental states and intentions or to empathize with the feelings of others. $[16,23,26]$. "I had no idea that other people communicated through subtle eye movements," says an adult with autism, "until I read it in a magazine five years ago." Such a capacity is a prerequisite for higher level appreciation of the minds of others and is part of this larger cognitive domain called theory of mind or social cognition, which is severely impaired in autism [26,27].

\subsection{Gaze Abnormalities in Autism: Eye Tracking Studies}

In the last decade, the use of eye-tracking methodology has allowed a better characterization of the social perception deficits in autism, particularly a lack of preference for the eyes. This methodology allows to objectively analyze gaze pattern during the viewing of naturalistic situations or during the performance of cognitive tasks. Studies with adults and children with ASD during visualization of naturalistic social scene have shown that they have a preference for non-social information (physical details of the environment) rather than for the social information (face and eyes of characters) [20,28-30].

In 2002, Klin and colleagues published the first paper using eye-tracking methodology in autism. They presented scenes from the film Who's Afraid of Virginia Woolf to study gaze pattern of adults with ASD and showed that they looked significantly less to the eyes of characters and more to non-social background areas in the scenes [28]. Since then, several studies have confirmed these social perception abnormalities in ASD and have shown that these abnormalities are already present earlier in development. Indeed, in children with ASD, a lack of preference for biological motion in general has been shown in a number of studies [31,32]. Two-yearold toddlers with autism have shown no preference for point-lights biological motion, contrary to typically developing controls [19]. Children with autism showed a preference for geometric patterns of movement rather than for social movement [33]. They will also look less to eyes and face areas and more to body and objects when watching scenes from a movie [34] and, when engaged in semi-naturalistic interaction with a familiar adult, they look significantly less to the face [35].

Interestingly, a recent study developed in our lab has allowed to show that gaze pattern in children with autism varies according to the type of stimuli that is used. When presented with four different types of stimuli (real characters movie, cartoon movie, real characters pictures and cartoon pictures) children with autism look less to the eyes in the situation that is more ecologically relevant (real characters movie) than in cartoons when compared to controls [36] (Figure 1).

Abnormalities in gaze pattern have also been shown in subjects with autism while performing tasks involving social cognition processes. Adults with autism have shown impairments in emotion recognition when presented with human pictures. The lower performance in this task was associated with abnormal visual strategy in face exploration [37]. This kind of impairment has also been described in children with autism, who were slower than controls to recognize emotions from human pictures. In this study, better emotion recognition in the autistic 


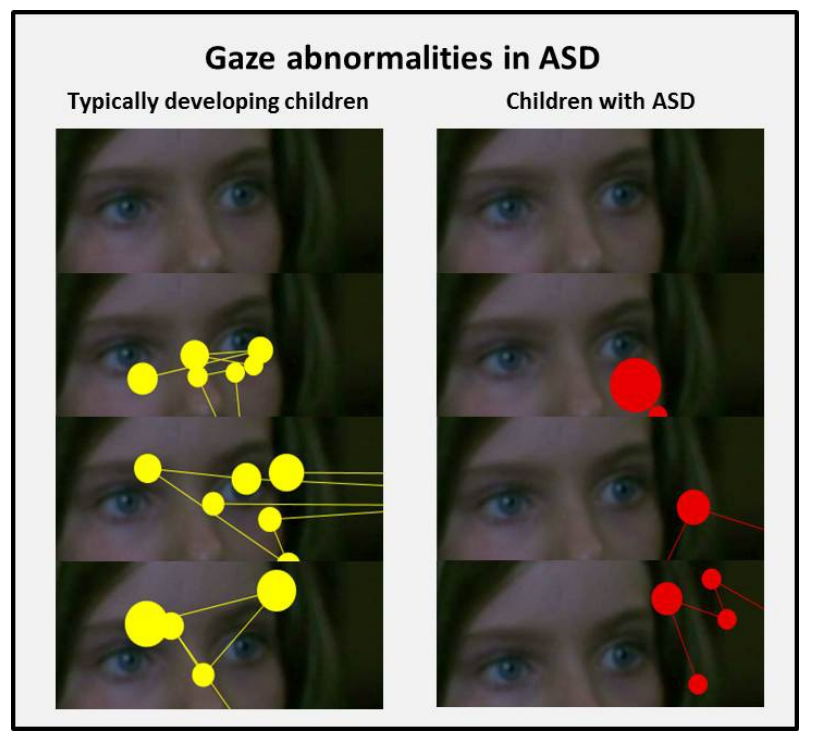

Figure 1. Example of characteristic gaze pattern to the eyes in three typically developing children (in yellow) and in three children with ASD (in red) during visualization of a social movie.

group was associated with increased gaze to the eyes [38].

These results from eye-tracking studies objectively demonstrate abnormalities in the processing of visual social information in ASD, which could underline difficulties in the comprehension of more complex social situations.

\subsection{Social Perception and Social Cognition: Implication of the Temporal Lobe}

The ability to recognize a specific individual within a social context is the foundation of social behavior. In less evolved mammals, this recognition is largely based on recognizing its specific individual smell. In contrast, non-human primates and humans recognize individuals mostly by their facial features and by the tone of their vocalizations. Consequently, our brain must have developed a specialized ability for social cognition, in both visual and auditory domains, to process "information which culminates in the accurate perception of the dispositions and intentions of other individuals" [1].

In the visual social domain, since the end of the 70's studies of single cells have indicated that specialized visual mechanisms exist in the STS of non-human primates and produce selective neural responses to such things as the movement of natural images of faces and bodies [5, 39]. In humans nothing was known about the functions of the STS until an fMRI study, published in 1996, showed an unexpected STS activation induced by a point light display depicting a moving body [40]. At the time, this was regarded as surprising, since this superior temporal lobe region was considered to be dedicated to auditory processing of speech sounds [41]. In a PET study published in the same year, Bonda and colleagues demonstrated that human motion stimuli selectively activated the inferior parietal region and the STS. Since these publications, a large series of papers have confirmed the implication of the STS in the perception of images moving in a natural biological way. Indeed, more recently Herrington and colleagues showed STS activation related to the observation of point lights displaying human movement compared to point lights displaying a moving wheel [42]. Additionally to global body dislocation, STS activation was found during the perception of eyes, face, mouth and hands movements $[2,15,43]$. Taken together, these studies strongly implicate the human STS and adjacent cortex in the perception of biological motion and point the STS as a key cortical structure for social cognition, suggesting that the initial analysis of visual social cues, which we call social perception, occurs within the STS [5].

In addition, studies have demonstrated that STS responds not only to biological movement itself but also to specific aspects of social gestures, including "the intentionality and appropriateness of biological motion" [4, $44,45]$. Indeed, STS activation has been reported in response to possible versus impossible human movements [46] and meaningful versus non-meaningful hand motions [47], as well as to the intentionality of other observed human actions including reaching-to-grasp movements of the arm and hand [48]. These data indicate that STS is concerned with more than just perceptual aspects of moving or movable body parts. Rather, networks in this brain region may analyze gaze and other movements to the extent that these cues meaningfully contribute to social communication.

Exceeding its role in perception of socially relevant movements, new data implicating the STS in more complex social cognition were published and have enlarged our knowledge about the role of the STS in this process. Indeed, STS has been implicated in auditory social perception as well as in visual social perception and in analysis and interpretation of the intention of other's, known as theory of mind (ToM).

In visual social cognition, gaze is undoubtedly essential, perhaps without a match in its significance as a biological signal. In a series of studies, Pelphrey and colleagues have investigated the degree to which STS activation is modulated by the context of the perceived eye movement. For example, they studied STS activation during an eye gaze perception when gaze shifts correctly or incorrectly following a visual target, or whether the eye gaze conveys the intention to engage in or withdraw from a social interaction. They have showed that the STS is sensitive to the social context within which a gaze shift occurs, i.e. whether the gaze is perceived as being con- 
sistent or inconsistent with the subject's expectation regarding the intention of the person making the eye movement [49]. In that study, which used a functional MRI (fMRI) paradigm with typically developing subjects, a strong effect of context was observed in the right posterior STS region: observation of gaze shifting away from a target (incongruent shifts) evoked a haemodynamic response with extended duration and greater amplitude compared to gaze shifting towards the target (congruent shifts). In a similar study from the same group, also performed in typically developing subjects, STS presented a greater response when participants viewed a reaching gesture incongruent with a prior emotional expression than when they viewed a reaching gesture congruent with the prior expression, regardless of whether expectations were induced by a positive or a negative emotional expression [45]. Consistent with prior studies in adults, the STS, middle temporal gyrus, and inferior parietal lobule were sensitive to the intentions underlying the stimulus character's eye movements. It has also been demonstrated that the STS region plays a critical role in processing eye gaze signals of approach and avoidance [50]. These findings suggest that achieving joint attention, a pivotal skill in social cognition, is facilitated by the analysis of sensory cues in the STS.

In the auditory social domain, voices, which can be thought of as "auditory faces", are at the center of human social interactions. fMRI studies have identified voiceselective areas in normal adults, located along the upper bank of the STS bilaterally [41]. Recognition of both familiar and non-familiar voices has also been found to activate the posterior STS [51]. In addition, there is increasing evidence that the STS also processes auditory action related information. For example, Bidet-Caulet and colleagues reported activity in the STS as participants heard footsteps. Other studies have shown greater STS activity associated with hearing of human actions, such as yawning or chewing, compared to hearing other environmental or mechanical actions [52].

Concerning results implicating the STS in theory of mind processes, Castelli and colleagues and Schultz and colleagues reported that the STS showed a significantly higher response to animations of moving geometric shapes that depicted complex social interactions than to animations depicting random motion [53,54]. Using movies of human actors engaged in structured goal-directed actions (e.g. cleaning the kitchen), Zacks and colleagues found that activity in the STS was enhanced when the agent switched from one action to another, suggesting that this region encodes the goal-structure of actions [55]. Both of these results are consistent with a role for a region of the STS cortex in representing intentional action, and not just biological motion.

Recently, brain imaging studies have explored the neural basis of normal variation in social performance. Studies performed in the general population have shown an association between subclinical individual traits of autism and anatomo-functional aspects of the STS. For instance, higher autistic trait rates were associated with thinner cortex most prominently in right STS [56]. A different study, also performed in the general population using VBM analysis showed that increased autistic trait scores were associated with decreased white matter volume in the posterior STS [57]. Furthermore, fMRI showed that the increase in cortical response associated to changes in gaze direction in the posterior STS is predicted by scores of autistic traits in typical adults [58]. Additionally, quantitative variation in the number of friends an individual declares on a web-based social networking service reliably predicted grey matter density in the right STS [59].

These and other findings increasingly support the implication of the STS in social perception and social cognition processes. Moreover, it helps to understand and interpret the brain imaging abnormalities described in ASD.

\section{TEMPORAL LOBE ABNORMALITIES IN AUTISM: NEW BRAIN IMAGING FINDINGS}

\subsection{Rest Functional PET and SPECT Data: Region Cerebral Blood Flow Studies}

In children with autism, PET (positron emission tomography) and SPECT (single photon emission tomography) studies have described localized bilateral temporal hypoperfusion. These rest functional abnormalities were centered in the STS and superior temporal gyrus $[10,14]$ (Figure 2A). In both studies, participants with autism and control groups were matched for age and developmental quotients. Children with idiopathic mental retardation constituted control groups so the findings could not be attributed to the developmental delay.

In a subsequent study, a correlation analysis was performed in order to investigate a putative relationship between regional rest cerebral blood flow (rCBF) and the clinical profile of 45 autistic children. Autistic behavior was evaluated with the Autism Diagnosis Interview (ADIR) [60]. Significant negative correlation was observed between $\mathrm{rCBF}$ and the ADI-R score in the left superior temporal gyrus. The higher the ADI-R score (the more severe autistic syndrome is), the lower $\mathrm{rCBF}$ is in this left temporal region [61].

In addition, Zilbovicius and colleagues performed an individual analysis of their data comparing each child with autism to the control group. We detected an individually significant temporal hypoperfusion in 16 of the 21 children with autism (77\%). Moreover, a replication 


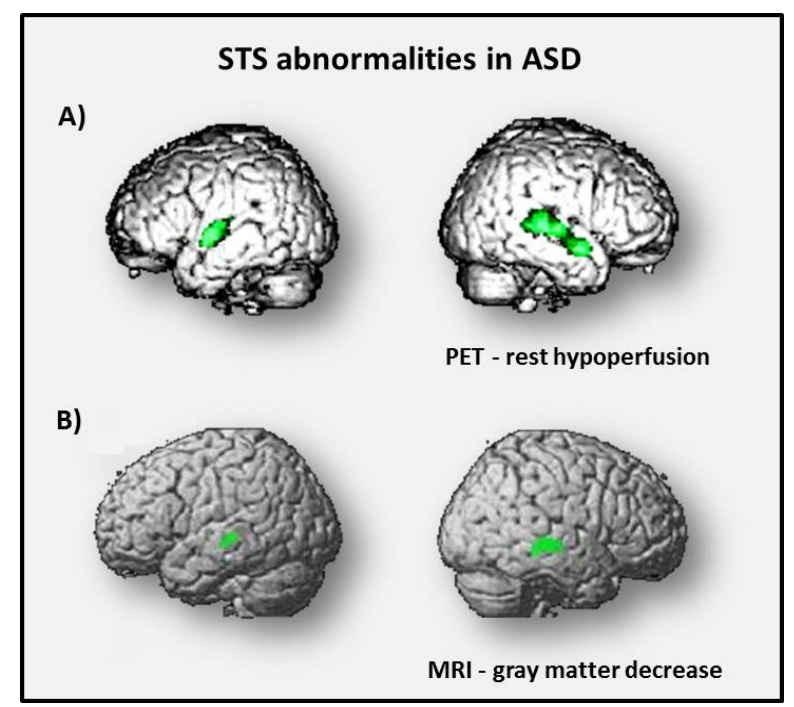

Figure 2. Brain imaging results in children with ASD. In these lateral views of the brain, regions in green are those that differ significantly in children with autism compared to controls in A) rest regional blood flow measured by PET and in B) concentration of gray matter measured by MRI.

study was performed in an additional group composed of 12 children with autism and confirmed both group and individual results [14]. Thus, the bilateral temporal hypoperfusion was confirmed in three independent groups of children with autism and provided the first robust evidence for temporal lobe dysfunction in school-aged children with autism.

More recently, whole brain multivariate classification, a new statistical strategy used to manage brain imaging data, have allowed the classification of ASD diagnosis based on PET data [62]. Temporal hypoperfusion was detected in $88 \%$ of the children with ASD, with extremely high rates of sensibility (91\%-41 correct classifications over 45 ASD subjects) and specificity (77\%-10 correct classifications over 13 control subjects), which could became a biomarker in autism.

\subsection{Anatomical MRI Data}

Quantitative structural imaging studies have benefited greatly from both new technologies for data acquisition and new image analysis approaches. Using parametric mesh-based analytic techniques, Levitt and colleagues showed significant differences in cortical sulci patterns in children with autism localized mainly in the frontal and temporal sulci [63]. By using a direct measurement of cortical thickness to examine the gray matter integrity and to explore the anatomical substrate of behavioral symptoms of ASD, Hadjikhani and colleagues found a local decrease of the gray matter in the ASD group in the inferior frontal gyrus, in the inferior parietal lobule and in the STS. In addition, cortical thinning in these regions was correlated with ASD symptom severity [64].

A pioneering study in ASD using voxel based morphometry (VBM) was published in 1999 by Abell and colleagues and showed fronto-temporal gray matter abnormalities [65]. Since then, VBM has benefited from substantial methodological improvements. Our team performed a MRI study using VBM and high-resolution 3DT1-weighted images acquired from 21 children with autism and 12 healthy control children. A significant bilateral decrease of grey matter was found in the STS of children with autism [11] (Figure 2B). The major finding of this study was the remarkable consistency between the bilateral temporal abnormalities found in autistic children by three independent MRI, PET [14] and SPECT studies [10]. A subsequent study performed in children with autism compared to controls showed that children with autism had reduced grey matter volumes in brain regions with critical socio-emotional function, such as the right fusiform gyrus and the STS [66].

The white matter structure also seems to be altered in subjects with autism when compared to controls. For instance, Barnea-Goraly and colleagues have used diffusion tensor imaging (DTI) to investigate white matter structural integrity in children and adolescents with autism [67]. Based on voxel-wise analysis, they found reduced fractional anisotropy (FA) values in brain regions that were implicated in theory-of-mind tasks (ventromedial prefrontal cortex, anterior cingulate, temporoparietal regions, amygdala), and in social cognition (fusiform gyrus and adjacent to superior temporal sulcus). Investigation of possible correlations between autistic symptoms and brain structure also point to an implication of abnormal anatomical connectivity in autism [68,69]. Anatomo-clinical correlations were mainly found in inferior frontal and superior temporal white matter regions, through which two main bundles, the arcuate and the uncinate fascicule pass [70]. In a recent study developed in our lab, we investigated the correlation between autism severity, measured by the ADI-R [60], and diffusion MRI parameters in children and adolescents with autism. Results showed that ADI scores correlated with FA decrease in superior temporal and frontal inferior white matter regions [71].

\subsection{Activation PET and MRI Studies}

Studies using fMRI have relied on different paradigms related to social processes to investigate differences in brain activity between subjects with autism and control subjects during performance of variable tasks [72].

\subsubsection{Auditory Social Processing}

Voice Studies

In a study developed in our lab, fMRI results point out 
the absence of activation of the "voice-selective area" in autism [73]. Significant differences in brain activation during voice perception were found in individuals with autism compared to healthy volunteers. In healthy volunteers, listening to voice compared to non-voice significantly activated a "voice-selective area” located bilaterally along the upper bank of the STS [41]. Voice perception in the ASD group did not yield activation of any other brain region relative to non-voice perception. In the ASD group, listening to voice and to non-voice sounds activated the same primary auditory regions. In addition, unlike the individual data obtained in controls, all but one subject with ASD failed to activate the "voice-selective area". The absence of activation of the "voice-selective area" in the ASD group was also confirmed by a direct comparison of the two groups' activation maps. The acoustic structure of the voice contains a large amount of socially relevant information, such as identity and emotional state. Absence of a preferential processing of these socially relevant stimuli is evidence of impairments in social perception in the auditory world.

\subsubsection{Visual Social Processing}

1) Face Processing Studies

A large amount of social information during basic communication situation is conveyed within faces. The processing of faces in individuals with autism appears to be atypically organized in comparison to the network observed in control subjects. Activations in the fusiform face area (FFA) [74], and the occipital face area are commonly reported as reduced in individuals with ASD (for review, see [75]. Schultz and colleagues were the first to use fMRI to study face perception in autistic subjects. They found significantly less activation of the middle aspect of the right FFA in 14 high functioning individuals with ASD compared to controls [76]. Hypoactivation of the FFA was replicated in a series of functional studies [77-79]. In the same path, Critchley and colleagues investigated whether high functioning people with ASD showed a different pattern of cortical activation when processing facial expressions. Nine autistic adults and 9 age-matched controls were asked to perform explicit (conscious) and implicit (unconscious) identification of emotional facial expressions. Autistics differed significantly from controls in the activation of the cerebellum, the mesolimbic, and temporal lobe cortical regions when observing facial expressions (consciously as well as unconsciously). Notably, they didn't activate a cortical FFA when explicitly appraising expressions [80].

2) Gaze Studies

Pelphrey and colleagues found abnormal STS activation in an eye gaze perception task in autistic adults. On congruent trials, subjects watched as a virtual actor looked towards a checkerboard that appeared in her visual field, confirming the subject's expectation regarding what the actor "ought to do" in this context. On incongruent trials, she looked towards empty space, violating the subject's expectation. In normal subjects incongruent trials evoked more activity in the STS and other brain regions linked to social cognition, indicating a strong effect of intention. The same brain regions were activated during observation of gaze shifts in subjects with autism, but did not differentiate congruent and incongruent trials, indicating that activity in these regions was not modulated by the context of the perceived gaze shift. These results indicate a difference in the response of brain regions underlying eye gaze processing in autism. The authors suggest that the lack of modulation of the STS region by gaze shifts that convey different intentions contributes to the eye gaze processing deficits associated with autism. These results were replicated in a similar study by the same group, with a different set of participants. As previously described, typical developing controls showed an incongruent $>$ congruent effect in the activation of the right posterior STS. Subjects with autism did not present this incongruent $>$ congruent effect, showing no difference in brain activation in the congruent or incongruent situations [13]. A recent meta-analysis on fMRI studies in autism highlighted that, when taking into account studies investigating activation during basic or complex social tasks, the brain region that is shown to be abnormally activated in subjects with autism is the STS [75].

\subsubsection{Social Cognition Studies}

Theory of Mind Studies

Individuals with ASD have difficulty attributing mental states to others and this may stem from difficulties in processing social information and cues from others. This mentalizing process is based on facial expression and eye gaze, but also on body movement, tone of voice and the more general context of the situation. In a study investigating mentalization process, Castelli and colleagues have studied cortical activation enhanced by animation of geometric figures. The animations depicted two traingles moving about on a screen in three different conditions: moving randomly, moving in a goal-directed fashion (chasing, fighting), and moving interactively with implied intentions (coaxing, tricking). The last condition frequently elicited descriptions in terms of mental states that viewers attributed to the triangles (mentalizing). Ten adults with ASD and 10 control adults were scanned while watching animated sequences. The ASD group gave fewer and less accurate descriptions of the mentalizing animations, but equally accurate descriptions of the other animations compared with controls. While viewing animations that elicited mentalizing (as opposed to randomly moving shapes) the control group showed increased activation in a previously identified mentalizing 
network (medial prefrontal cortex, STS and temporal poles). The ASD group showed less activation than the control group in all these regions. However, one additional region, the extrastriate cortex, which was highly active when watching animations that elicited mentalizing, showed the same amount of increased activation in both groups. In the autism group this extrastriate region showed reduced functional connectivity with the STS [12]. More recently, a study showed that signal intensity of the left anterior STS is related to the performance of ToM task [81].

\section{GENERAL CONCLUSION}

Researches developed over the last decade have helped to better characterize the major impairments in social cognition that consist the core characteristic of autism. On the behavioral level, thanks to new methodologies such as eye-tracking, we have a better understanding of how autistic subjects perceive the world around them. A general lack of preference for biological motion and social stimuli, which can be found very early in typical development, has been systematically described. More particularly, a lack of preference for the eyes is a key feature in social cognition impairments associated to autism. On the brain level, several studies have found anatomical and functional abnormalities in autism, particularly located on the STS. These STS abnormalities are characterized by decreased grey matter concentration, rest hypoperfusion and abnormal activation patterns during social cognition tasks. The STS is known to be a critical region for social cognition and is implicated in several steps of social interactions: from auditory and visual social perception (voice, gestures, facial displays of emotions and eye gazes perception) to more complex social cognition processes (theory of mind and mentalizing). In addition, the STS is also highly connected with other regions of the social brain such as the FFA, the orbitofrontal cortex and the amygdala. All these regions were found to be abnormally activated in ASD during tasks implicating social cognition. The increasing knowledge being acquired on the STS role in social cognition process helps to understand and interpret brain abnormalities described in autism.

Data reviewed in this paper support the hypothesis that abnormalities in the STS could be the first step in the cascade of neural phenomena underlying autism. These early developmental neural abnormalities of the STS would lead to abnormal connectivity among key regions of the social brain in autism, which could be account for the observed impairments in social perception and social cognition processes. Taken together, these data provide new outlook into the understanding of ASD, supporting evidence of a global deficit in the perception of socially relevant stimuli, particularly in gaze processing. Therefore, it could help to develop new therapeutical approaches, focusing on social perception process, mainly early gaze interaction, to stimulate the development of a "social expertise" and to improve social cognition in autism.

\section{REFERENCES}

[1] Brothers, L., Ring, B. and Kling, A. (1990) Response of neurons in the macaque amygdala to complex social stimuli. Behavioural Brain Research, 41, 199-213. doi:10.1016/0166-4328(90)90108-Q

[2] Kaiser, M.D., Hudac, C.M., Shultz, S., Lee, S.M., Cheung, C., et al. (2010) Neural signatures of autism. Proceedings of the National Academy of Sciences of the United States of America, 107, 21223-21228. doi:10.1073/pnas.1010412107

[3] Adolphs, R. (2003) Cognitive neuroscience of human social behaviour. Nature Reviews Neuroscience, 4, 165178. doi:10.1038/nrn1056

[4] Thompson, J. and Parasuraman, R. (2012) Attention, biological motion, and action recognition. Neuroimage, 59, 4-13. doi:10.1016/j.neuroimage.2011.05.044

[5] Allison, T., Puce, A. and McCarthy, G. (2000) Social perception from visual cues, role of the STS region. Trends in Cognitive Sciences, 4, 267-278. doi:10.1016/S1364-6613(00)01501-1

[6] Bonda, E., Petrides, M., Ostry, D. and Evans, A. (1996) Specific involvement of human parietal systems and the amygdala in the perception of biological motion. Journal of Neuroscience, 16, 3737-3744.

[7] Pelphrey, K.A., Morris, J.P. and McCarthy, G. (2005) Neural basis of eye gaze processing deficits in autism. Brain, 128, 1038-1048. doi:10.1093/brain/awh404

[8] Mosconi, M.W., Mack, P.B., McCarthy, G. and Pelphrey, K.A. (2005) Taking an "intentional stance" on eye-gaze shifts: A functional neuroimaging study of social perception in children. Neuroimage, 27, 247-252. doi:10.1016/j.neuroimage.2005.03.027

[9] Pelphrey, K.A., Morris, J.P., Michelich, C.R., Allison, T. and McCarthy, G. (2005) Functional anatomy of biological motion perception in posterior temporal cortex: An FMRI study of eye, mouth and hand movements. Cereb Cortex, 15, 1866-1876. doi:10.1093/cercor/bhi064

[10] Ohnishi, T., Matsuda, H., Hashimoto, T., Kunihiro, T., Nishikawa, M., et al. (2000) Abnormal regional cerebral blood flow in childhood autism. Brain, 123, 1838-1844. doi:10.1093/brain/123.9.1838

[11] Boddaert, N., Chabane, N., Gervais, H., Good, C.D., Bourgeois, M., et al. (2004) Superior temporal sulcus anatomical abnormalities in childhood autism: A voxelbased morphometry MRI study. Neuroimage, 23, 364-369. doi:10.1016/j.neuroimage.2004.06.016

[12] Castelli, F., Frith, C., Happe, F. and Frith, U. (2002) Autism, Asperger syndrome and brain mechanisms for the attribution of mental states to animated shapes. Brain, 
125, 1839-1849. doi:10.1093/brain/awf189

[13] Pelphrey, K.A., Shultz, S., Hudac, C.M. and Vander Wyk, B.C. (2011) Research review: Constraining heterogeneity, the social brain and its development in autism spectrum disorder. Journal of Child Psychology and Psychiatry, 52, 631-644. doi:10.1111/j.1469-7610.2010.02349.x

[14] Zilbovicius, M., Boddaert, N., Belin, P., Poline, J.B., Remy, P., et al. (2000) Temporal lobe dysfunction in childhood autism: A PET study. Positron emission tomogramphy. American Journal of Psychiatry, 157, 1988-1993. doi:10.1176/appi.ajp.157.12.1988

[15] Zilbovicius, M., Meresse, I., Chabane, N., Brunelle, F., Samson, Y., et al. (2006) Autism, the superior temporal sulcus and social perception. Trends in Neuroscience, 29, 359-366. doi:10.1016/j.tins.2006.06.004

[16] Baron-Cohen, S., Ring, H., Moriarty, J., Schmitz, B., Costa, D., et al. (1994) Recognition of mental state terms. Clinical findings in children with autism and a functional neuroimaging study of normal adults. British Journal of Psychiatry, 165, 640-649. doi:10.1192/bjp.165.5.640

[17] Frith, C.D. and Frith, U. (1999) Interacting minds-A biological basis. Science, 286, 1692-1695. doi:10.1126/science.286.5445.1692

[18] Bardi, L., Regolin, L. and Simion, F. (2011) Biological motion preference in humans at birth, role of dynamic and configural properties. Developmental Science, 14, 353-359.

[19] Klin, A., Lin, D.J., Gorrindo, P., Ramsay, G. and Jones, W. (2009) Two-year-olds with autism orient to non-social contingencies rather than biological motion. Nature, 459, 257-261. doi:10.1038/nature07868

[20] Jones, W., Carr, K. and Klin, A. (2008) Absence of preferential looking to the eyes of approaching adults predicts level of social disability in 2-year-old toddlers with autism spectrum disorder. Archives of General Psychiatry, 65, 946-954. doi:10.1001/archpsyc.65.8.946

[21] Pavlova, M.A. (2012) Biological motion processing as a hallmark of social cognition. Cereb Cortex, 22, 981-995. doi:10.1093/cercor/bhr156

[22] Farroni, T., Csibra, G., Simion, F. and Johnson, M.H. (2002) Eye contact detection in humans from birth. Proceedings of the National Academy of Sciences of the United States of America, 99, 9602-9605. doi:10.1073/pnas.152159999

[23] Klin, A., Jones, W., Schultz, R. and Volkmar, F. (2003) The enactive mind, or from actions to cognition, lessons from autism. Philosophical Transactions of the Royal Society B: Biological Sciences, 358, 345-360. doi:10.1098/rstb.2002.1202

[24] Senju, A., Kikuchi, Y., Hasegawa, T., Tojo, Y. and Osanai, H. (2008) Is anyone looking at me? Direct gaze detection in children with and without autism. Brain and Cognition, 67, 127-139. doi:10.1016/j.bandc.2007.12.001

[25] Frith, C.D. and Frith, U. (2012) Mechanisms of social cognition. Annual Review of Psychology, 63, 287-313. doi:10.1146/annurev-psych-120710-100449

[26] Frith, U., Morton, J. and Leslie, A.M. (1991) The cognitive basis of a biological disorder, autism. Trends in $\mathrm{Neu}$ - roscience, $14,433-438$. doi:10.1016/0166-2236(91)90041-R

[27] Baron-Cohen, S., Ring, H.A., Wheelwright, S., Bullmore, E.T., Brammer, M.J., et al. (1999) Social intelligence in the normal and autistic brain: An fMRI study. European Journal of Neuroscience, 11, 1891-1898. doi:10.1046/j.1460-9568.1999.00621.X

[28] Klin, A., Jones, W., Schultz, R., Volkmar, F. and Cohen, D. (2002) Visual fixation patterns during viewing of naturalistic social situations as predictors of social competence in individuals with autism. Archives of General Psychiatry, 59, 809-816. doi:10.1001/archpsyc.59.9.809

[29] Speer, L.L., Cook, A.E., McMahon, W.M. and Clark, E. (2007) Face processing in children with autism, effects of stimulus contents and type. Autism, 11, 265-277. doi:10.1177/1362361307076925

[30] Chawarska, K., Klin, A., Paul, R., Macari, S. and Volkmar, F. (2009) A prospective study of toddlers with ASD: Short-term diagnostic and cognitive outcomes. Journal of Child Psychology and Psychiatry, 50, 1235-1245. doi:10.1111/j.1469-7610.2009.02101.x

[31] Falck-Ytter, T. and von Hofsten, C. (2011) How special is social looking in ASD: A review. Progress in Brain Research, 189, 209-222. doi:10.1016/B978-0-444-53884-0.00026-9

[32] Boraston, Z. and Blakemore, S.J. (2007) The application of eye-tracking technology in the study of autism. Journal of Physiology, 581, 893-898. doi:10.1113/jphysiol.2007.133587

[33] Pierce, K., Conant, D., Hazin, R., Stoner, R. and Desmond, J. (2011) Preference for geometric patterns early in life as a risk factor for autism. Archives of General Psychiatry, 68, 101-109. doi:10.1001/archgenpsychiatry.2010.113

[34] Rice, K., Moriuchi, J.M., Jones, W. and Klin, A. (2012) Parsing heterogeneity in autism spectrum disorders, visual scanning of dynamic social scenes in school-aged children. Journal of the American Academy of Child and Adolescent Psychiatry, 51, 238-248. doi:10.1016/j.jaac.2011.12.017

[35] Noris, B., Nadel, J., Barker, M., Hadjikhani, N. and Billard, A. (2012) Investigating gaze of children with ASD in naturalistic settings. PLoS One, 7, e44144. doi:10.1371/journal.pone.0044144

[36] Saitovitch, A., Bargiacchi, A., Chabane, N., Philippe, A., Samson, Y. and Zilbovicius, M. (2013) Studying Gaze abnormalities in autism, Which type of stimulus to use? Submitted.

[37] Pelphrey, K.A., Sasson, N.J., Reznick, J.S., Paul, G., Goldman, B.D., et al. (2002) Visual scanning of faces in autism. Journal of Autism and Developmental Disorders, 32, 249-261. doi:10.1023/A:1016374617369

[38] Bal, E., Harden, E., Lamb, D., Van Hecke, A.V., Denver, J.W., et al. (2010) Emotion recognition in children with autism spectrum disorders, relations to eye gaze and autonomic state. Journal of Autism and Developmental Disorders, 40, 358-370. doi:10.1007/s10803-009-0884-3

[39] Keysers, C. and Perrett, D.I. (2004) Demystifying social 
cognition: A Hebbian perspective. Trends in Cognitive Science, 8, 501-507. doi:10.1016/j.tics.2004.09.005

[40] Howard, R.J., Brammer, M., Wright, I., Woodruff, P.W., Bullmore, E.T., et al. (1996) A direct demonstration of functional specialization within motion-related visual and auditory cortex of the human brain. Current Biology, 6, 1015-1019. doi:10.1016/S0960-9822(02)00646-2

[41] Belin, P., Zatorre, R.J., Lafaille, P., Ahad, P. and Pike, B. (2000) Voice-selective areas in human auditory cortex. Nature, 403, 309-312. doi:10.1038/35002078

[42] Herrington, J.D., Nymberg, C. and Schultz, R.T. (2011) Biological motion task performance predicts superior temporal sulcus activity. Brain and Cognition, 77, 372381. doi:10.1016/j.bandc.2011.09.001

[43] Neuhaus, E., Beauchaine, T.P. and Bernier, R. (2010) Neurobiological correlates of social functioning in autism. Clinical Psychology Review, 30, 733-748. doi:10.1016/j.cpr.2010.05.007

[44] Pavlova, M., Sokolov, A.N., Birbaumer, N. and Krageloh-Mann, I. (2008) Perception and understanding of others' actions and brain connectivity. Journal of Cognitive Neuroscience, 20, 494-504. doi:10.1162/jocn.2008.20034

[45] Wyk, B.C., Hudac, C.M., Carter, E.J., Sobel, D.M. and Pelphrey, K.A. (2009) Action understanding in the superior temporal sulcus region. Psychological Science, 20, 771-777. doi:10.1111/j.1467-9280.2009.02359.x

[46] Stevens, J.A., Fonlupt, P., Shiffrar, M. and Decety, J. (2000) New aspects of motion perception, selective neural encoding of apparent human movements. Neuroreport, 11, 109-115. doi:10.1097/00001756-200001170-00022

[47] Decety, J., Grezes, J., Costes, N., Perani, D., Jeannerod, M., et al. (1997) Brain activity during observation of actions. Influence of action content and subject's strategy. Brain, 120, 1763-1777. doi:10.1093/brain/120.10.1763

[48] Pelphrey, K.A., Morris, J.P. and McCarthy, G. (2004) Grasping the intentions of others, the perceived intentionality of an action influences activity in the superior temporal sulcus during social perception. Journal of Cognitive Neuroscience, 16, 1706-1716. doi:10.1162/0898929042947900

[49] Pelphrey, K.A., Singerman, J.D., Allison, T. and McCarthy, G. (2003) Brain activation evoked by perception of gaze shifts: The influence of context. Neuropsychologia, 41, 156-170. doi:10.1016/S0028-3932(02)00146-X

[50] Pelphrey, K.A., Viola, R.J. and McCarthy, G. (2004) When strangers pass, processing of mutual and averted social gaze in the superior temporal sulcus. Psychological Science, 15, 598-603. doi:10.1111/j.0956-7976.2004.00726.x

[51] Kriegstein, K.V. and Giraud, A.L. (2004) Distinct functional substrates along the right superior temporal sulcus for the processing of voices. Neuroimage, 22, 948-955. doi:10.1016/j.neuroimage.2004.02.020

[52] Lewis, J.W., Frum, C., Brefczynski-Lewis, J.A., Talkington, W.J., Walker, N.A., et al. (2011) Cortical network differences in the sighted versus early blind for recognition of human-produced action sounds. Human Brain Mapping, 32, 2241-2255. doi:10.1002/hbm.21185
[53] Castelli, F., Happe, F., Frith, U. and Frith, C. (2000) Movement and mind: A functional imaging study of perception and interpretation of complex intentional movement patterns. Neuroimage, 12, 314-325. doi:10.1006/nimg.2000.0612

[54] Schultz, J., Imamizu, H., Kawato, M. and Frith, C.D. (2004) Activation of the human superior temporal gyrus during observation of goal attribution by intentional objects. Journal of Cognitive Neuroscience, 16, 1695-1705. doi:10.1162/0898929042947874

[55] Zacks, J.M., Braver, T.S., Sheridan, M.A., Donaldson, D.I., Snyder, A.Z., et al. (2001) Human brain activity time-locked to perceptual event boundaries. Nature Neuroscience, 4, 651-655. doi:10.1038/88486

[56] Wallace, G.L., Shaw, P., Lee, N.R., Clasen, L.S., Raznahan, A., et al. (2012) Distinct cortical correlates of autistic versus antisocial traits in a longitudinal sample of typically developing youth. Journal of Neuroscience, 32, 48564860. doi:10.1523/JNEUROSCI.6214-11.2012

[57] von dem Hagen, E.A., Nummenmaa, L., Yu, R., Engell, A.D., Ewbank, M.P., et al. (2011) Autism spectrum traits in the typical population predict structure and function in the posterior superior temporal sulcus. Cereb Cortex, 21, 493-500. doi:10.1093/cercor/bhq062

[58] Nummenmaa, L., Engell, A.D., von dem Hagen, E., Henson, R.N. and Calder, A.J. (2012) Autism spectrum traits predict the neural response to eye gaze in typical individuals. Neuroimage, 59, 3356-3363. doi:10.1016/j.neuroimage.2011.10.075

[59] Kanai, R., Bahrami, B., Roylance, R. and Rees, G. (2012) Online social network size is reflected in human brain structure. Proceedings of the Royal Society B: Biological Sciences, 279, 1327-1334. doi:10.1098/rspb.2011.1959

[60] Lord, C., Rutter, M. and Le Couteur, A. (1994) Autism diagnostic interview-revised: A revised version of a diagnostic interview for caregivers of individuals with possible pervasive developmental disorders. Journal of Autism and Developmental Disorders, 24, 659-685. doi:10.1007/BF02172145

[61] Gendry Meresse, I., Zilbovicius, M., Boddaert, N., Robel, L., Philippe, A., et al. (2005) Autism severity and temporal lobe functional abnormalities. Annals of Neurology, 58, 466-469. doi:10.1002/ana.20597

[62] Duchesnay, E., Cachia, A., Boddaert, N., Chabane, N., Mangin, J.F., et al. (2011) Feature selection and classification of imbalanced datasets, application to PET images of children with autistic spectrum disorders. Neuroimage, 57, 1003-1014. doi:10.1016/j.neuroimage.2011.05.011

[63] Levitt, J.G., Blanton, R.E., Smalley, S., Thompson, P.M., Guthrie, D., et al. (2003) Cortical sulcal maps in autism. Cereb Cortex, 13, 728-735. doi:10.1093/cercor/13.7.728

[64] Hadjikhani, N., Joseph, R.M., Snyder, J. and TagerFlusberg, H. (2006) Anatomical differences in the mirror neuron system and social cognition network in autism. Cereb Cortex, 16, 1276-1282. doi:10.1093/cercor/bhj069

[65] Abell, F., Krams, M., Ashburner, J., Passingham, R., Friston, K., et al. (1999) The neuroanatomy of autism: A voxel-based whole brain analysis of structural scans. 
Neuroreport, 10, 1647-1651. doi:10.1097/00001756-199906030-00005

[66] McAlonan, G.M., Cheung, V., Cheung, C., Suckling, J., Lam, G.Y., et al. (2005) Mapping the brain in autism: A voxel-based MRI study of volumetric differences and intercorrelations in autism. Brain, 128, 268-276. doi:10.1093/brain/awh332

[67] Barnea-Goraly, N., Lotspeich, L.J. and Reiss, A.L. (2010) Similar white matter aberrations in children with autism and their unaffected siblings: A diffusion tensor imaging study using tract-based spatial statistics. Archives of $\mathrm{Ge}$ neral Psychiatry, 67, 1052-1060. doi:10.1001/archgenpsychiatry.2010.123

[68] Just, M.A., Cherkassky, V.L., Keller, T.A. and Minshew, N.J. (2004) Cortical activation and synchronization during sentence comprehension in high-functioning autism, evidence of underconnectivity. Brain, 127, 1811-1821. doi:10.1093/brain/awh199

[69] Fouque, A.L., Fillard, P., Bargiacchi, A., Cachia, A., Zilbovicius, M., et al. (2011) Voxelwise multivariate statistics and brain-wide machine learning using the full diffusion tensor. Medical Image Computing and Computer Assisted Intervention, 14, 9-16.

[70] Mori, S., Oishi, K., Jiang, H., Jiang, L., Li, X., et al. (2008) Stereotaxic white matter atlas based on diffusion tensor imaging in an ICBM template. Neuroimage, 40, 570-582. doi:10.1016/j.neuroimage.2007.12.035

[71] Bargiacchi, A., Cachia, A., Chabane, N., Boddaert, N., Philippe, A., Brunelle, F., Poupon, C., Mouren, M.C., Samson, Y., Laurier, L. and Zilbovicius, M. (2013) Correlation of white matter integrity and autism clinical symptomatology: A whole-brain diffusion MRI study. Submitted.

[72] Philip, R.C., Dauvermann, M.R., Whalley, H.C., Baynham, K., Lawrie, S.M., et al. (2011) A systematic review and meta-analysis of the fMRI investigation of autism spectrum disorders. Neuroscience \& Biobehavioral Reviews, 36, 901-942.

[73] Gervais, H., Belin, P., Boddaert, N., Leboyer, M., Coez, A., et al. (2004) Abnormal cortical voice processing in autism. Nature Neuroscience, 7, 801-802. doi:10.1038/nn1291
[74] Haxby, J.V., Hoffman, E.A. and Gobbini, M.I. (2002) Human neural systems for face recognition and social communication. Biological Psychiatry, 51, 59-67. doi:10.1016/S0006-3223(01)01330-0

[75] Philip, R.C., Dauvermann, M.R., Whalley, H.C., Baynham, K., Lawrie, S.M., et al. (2012) A systematic review and meta-analysis of the fMRI investigation of autism spectrum disorders. Neuroscience \& Biobehavioral Reviews, 36, 901-942. doi:10.1016/j.neubiorev.2011.10.008

[76] Schultz, R.T., Gauthier, I., Klin, A., Fulbright, R.K., Anderson, A.W., et al. (2000) Abnormal ventral temporal cortical activity during face discrimination among individuals with autism and Asperger syndrome. Archives of General Psychiatry, 57, 331-340. doi:10.1001/archpsyc.57.4.331

[77] Pierce, K., Muller, R.A., Ambrose, J., Allen, G. and Courchesne, E. (2001) Face processing occurs outside the fusiform "face area" in autism, evidence from functional MRI. Brain, 124, 2059-2073. doi:10.1093/brain/124.10.2059

[78] Critchley, H.D., Daly, E.M., Bullmore, E.T., Williams, S.C., Van Amelsvoort, T., et al. (2000) The functional neuroanatomy of social behaviour, changes in cerebral blood flow when people with autistic disorder process facial expressions. Brain, 123, 2203-2212. doi:10.1093/brain/123.11.2203

[79] Hubl, D., Bolte, S., Feineis-Matthews, S., Lanfermann, H., Federspiel, A., et al. (2003) Functional imbalance of visual pathways indicates alternative face processing strategies in autism. Neurology, 61, 1232-1237. doi:10.1212/01.WNL.0000091862.22033.1A

[80] Critchley, H., Daly, E., Phillips, M., Brammer, M., Bullmore, E., et al. (2000) Explicit and implicit neural mechanisms for processing of social information from facial expressions: A functional magnetic resonance imaging study. Human Brain Mapping, 9, 93-105. doi:10.1002/(SICI)1097-0193(200002)9:2<93::AID-HB M4>3.0.CO;2-Z

[81] Otsuka, Y., Osaka, N., Ikeda, T. and Osaka, M. (2009) Individual differences in the theory of mind and superior temporal sulcus. Neuroscience Letters, 463, 150-153. doi:10.1016/j.neulet.2009.07.064 